\title{
The role of phase change materials for the sustainable energy
}

\author{
Marta Kuta1,a, Dominika Matuszewska ${ }^{1}$ and Tadeusz Michał Wójcik1 \\ ${ }^{1}$ A GH University of Science and Technology, Faculty of Energy and Fuels, Department of Thermal and Fluid Flow Machines, \\ al. A. Mickiewicza 30, 30-059 Krakow
}

\begin{abstract}
Unceasing global economic development leads to continuous increase of energy demand. Considering the limited conventional resources of energy as well as impact on the environment associated with its use, it is important to focus on the rational management of energy resources and on supporting the development of new technologies related to both conventional and renewable energy resources. In a number of cases the use of phase change materials (PCMs) turns out to be a reasonable solution. This paper contains a summary of well-studied and known, previously used solutions based on phase change materials as well as novel possibilities, which are under development. It has been decided to investigate this topic due to the wide range of highly effective solutions. The review is focused on selected applications of PCMs for technologies which are designed to improve energy efficiency and on PCMs used in technologies based on renewable energy sources.
\end{abstract}

\section{Introduction}

With the dynamic economic development and consequently incessant increase of the demand for heat and electricity and also increasing requirements on life comfort, we need to face the necessity of rational management of available resources. Among the possibilities of working on this challenge we can list reducing the gap between the demand and supply of energy. For that purpose thermal energy storage (TES) appears as a good solution. Latent heat storage is one of the most efficient way of storing thermal energy. The use of phase change materials is based on the use of latent heat and it is characterised by advantages as [1]: high storage density (as compared to sensible heat) and low difference between temperatures of heat storage and release. In that case PCMs have been used in latent heat thermal storage systems for solar power engineering and heat pumps [1,2]. Another and also one of the first applications with the use of PCMs for thermal storage is building application [3]. It is also important to improve existing and develop new technologies to support the use of renewable energy resources. Phase change materials can be used successfully in this area. The aim of this paper is to review applications of phase change materials for technologies related for sustainable energy.

\section{Phase change materials}

Applications of phase change materials for new technologies are valuable. First of all, because of its ability to absorb the heat during the transition and store it for specific and distinctive amount of time, according to the type of material. Fig. 1 shows how phase change materials work based on latent heat.

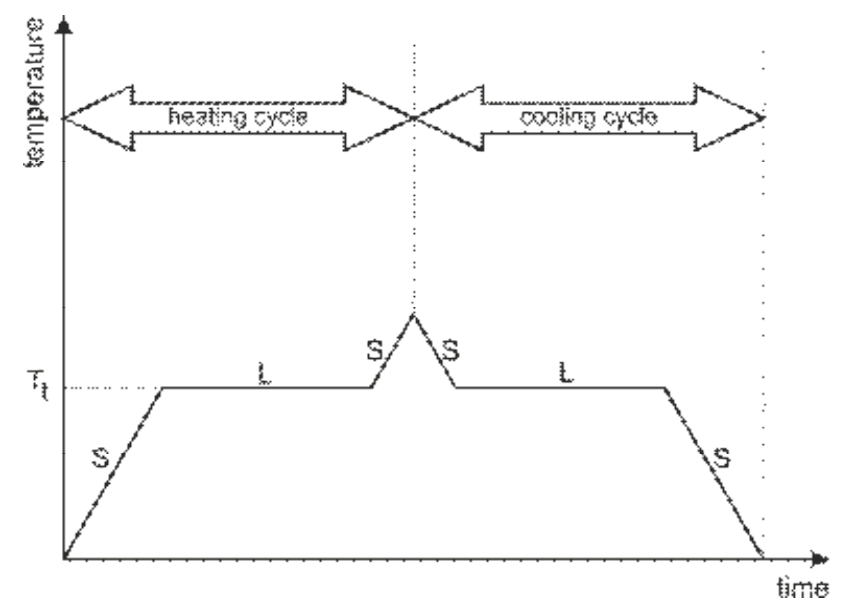

Figure 1. Schematic heat curve for phase change material; Ssensible heat, $\mathrm{L}$-latent heat, $\mathrm{T}_{\mathrm{t}}$ - temperature of phase transition.

There are several conditions that determine the possibility and profitability of using the PCMs. The first essential aspect is the temperature range of phase transition which need to be adequate to the application. Nearly always it is important that the material is characterized by possibly high latent heat of transition and specific heat and thermal conductivity. Next important features are: no degradation after many operation cycles, stability of properties at subsequent cycles and minimal subcooling, minimal volume change and gas generation on transition. It is also required that PCM is non-toxic and non-corrosive, non-flammable, non-explosive and easy to recycle, environment friendly. From the economic point of view it is important that price is reasonably low enabling the use of PCM for wider group of applications.

\footnotetext{
a Corresponding author: marta.kuta@agh.edu.pl
} 
There are several criteria used to group PCMs. Fig. 2 and Fig. 3 show how phase change materials can be grouped according to the type of transition (Fig. 2) and to the type of materials (Fig. 3). As it can be seen in table 1 PCMs can be identified as: solid-liquid, liquid-solid, liquid-gas, gas-liquid, solid-solid. The best known and most frequently used are solid-liquid PCMs. It is related to high availability and good thermophysical properties of S-L PCMs. Phase change materials from the solidsolid group are not that widely used because of typically smaller storage capability, however lately S-S PCMs have become interesting because of several advantages such as: no volume change, no leakage or gas generation during the transition.

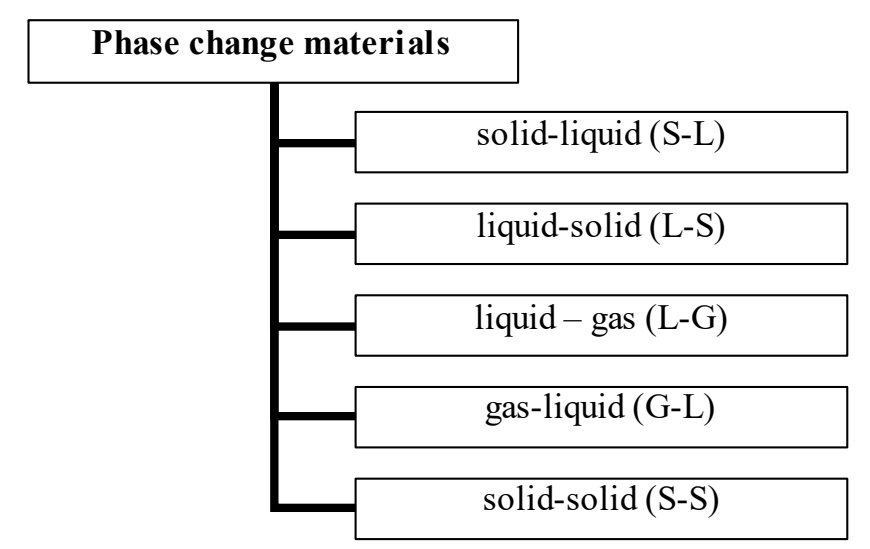

Figure 2. Phase change materials classification - type of transition.

As it has been described before the best known are S-L PCMs. Most researches refer to their properties which are similar within every group. In general, PCMs with solid-liquid phase transformations can be classified into: organic, inorganic or eutectics. Following figure (Fig. 3) shows more detailed classification.

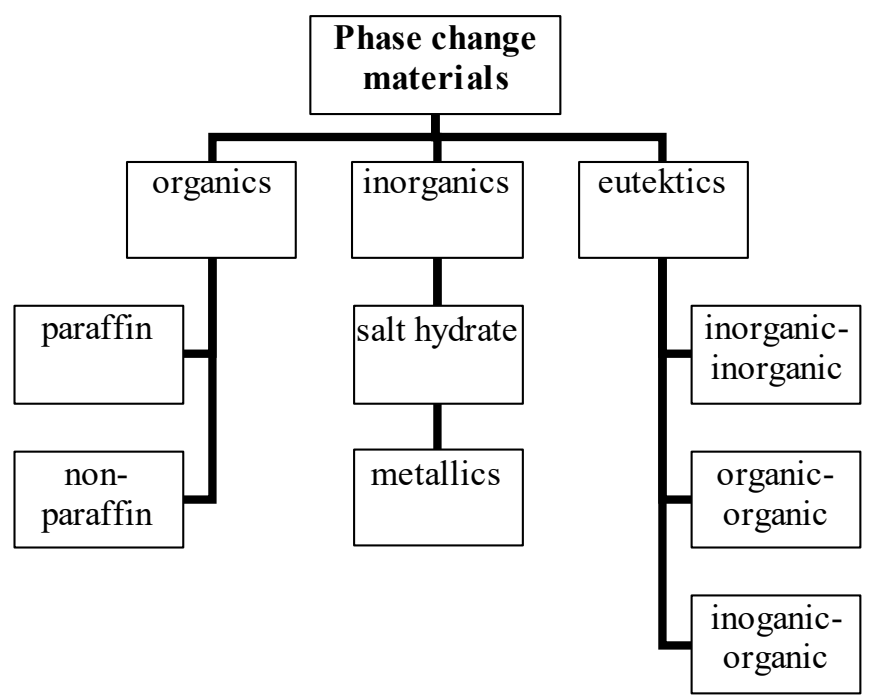

Figure 3. Phase change materials classification.

There is available wide range of phase change materials characterized by different properties. It creates the possibility to use them for various applications.

\section{Phase change materials for building applications}

\subsection{PCMs integrated with buildings envelopes}

A building envelope can be described [4] as a part of the building which separates its indoor and outdoor environments. Buildings envelopes plays an important role in maintaining proper internal conditions, especially important are components such as walls, roof, foundation, thermal insulation, external shading elements. Among the various studies on improvement of buildings envelopes properties we can find that many of them are related to application of phase change materials. Some examples of research conducted in this area are presented in this section, paying attention to walls, windows and shutters, roofs and floors.

\subsubsection{Walls}

There is several solutions considering phase change materials integration into the walls $[5,6]$ :

- direct incorporation and immersion,

- shape-stabilized PCM composite,

- micro-encapsulation of PCMs,

- macro-encapsulation of PCMs.

Many researchers conduct their researches on those methods to minimize defects and some disadvantages associated with their use.

Phase change materials can be incorporated into the concrete directly. Many researches have been conducted to test this possibility. Lee et al. [7] compared, with good results, the thermal storage performance of ordinary concrete blocks with two different blocks, modified by addition of PCMs - a commercial Butyl Stearate (Emerest 2326), and the other commercial Parafin (Unicere 55). Barreneche et al. [8] have also investigated the possibility of PCMs buildings applications. Additionally authors have compared difference in effect between incorporating PCMs into different types of building materials. They observed how beneficial is addition of various amount of PCMs into both concrete and gypsium. However, the results were not conclusive. Many researches in this area ended with conclusion that that direct incorporation of PCMs may involve leakage after many work cycles. It can affect mechanical properties of the concrete and its durability $[6,9]$.

Use of shape-stable composites enables to avoid the leakage $[10,11]$. They can be made on the basis of various kinds of components such us [12]: polyethylene, styrene and butadiene. Shape-stable Composites are generally characterized by $[8,13,14]$ :

- large specific heat,

- high enough thermal conductivity,

- ability to keep the shape of PCM stabilised over the phase change process,

- good performance of multiple thermal cycles over a long period.

To avoid the leakage, phase change materials can also be incorporated into the wall with the use of microor macroencapsulation $[15,16]$. 
Macroencapsulation involves placing the material in the sealed container. The package can have various shapes such as spheres, tubes, panels or similar [8, 17]. Macroencapsulated materials can be used as a part of the wall or independently. Many possible solutions for macroencapsulation addressed to different types of PCMs are available. Fukahori et al. [18] designed and built capsule with very good corrosive resistance and cycling performance for metallic PCMs. Alam et al. [19] presents technique to encapsulate PCMs with melting point in the range of $120-350^{\circ} \mathrm{C}$.

Microencapsulation consists of enclosed a phase change material in a microscopic spherical or rod-shaped or irregular shape capsules with diameter in the range of $1 \mu \mathrm{m}$ to $1 \mathrm{~mm}[9,13]$. There are several physical and chemical methods for the production of microcapsules such us [20, 21]: pan coating, spray drying, coacervation, sol-gel, interfacial polymerization and many others.

Selection of the best suited methods for incorporation of PCMs into the wall is dictated by practical and economic reasons.

\subsubsection{Windows and window shutter}

Xiang et al. [22] conducted the research and numerical investigation on window-based cooling unit filled with phase change materials. Fig. 4 presents the plan of the office with cooling unit at night (upper picture) and during the day (lower picture).
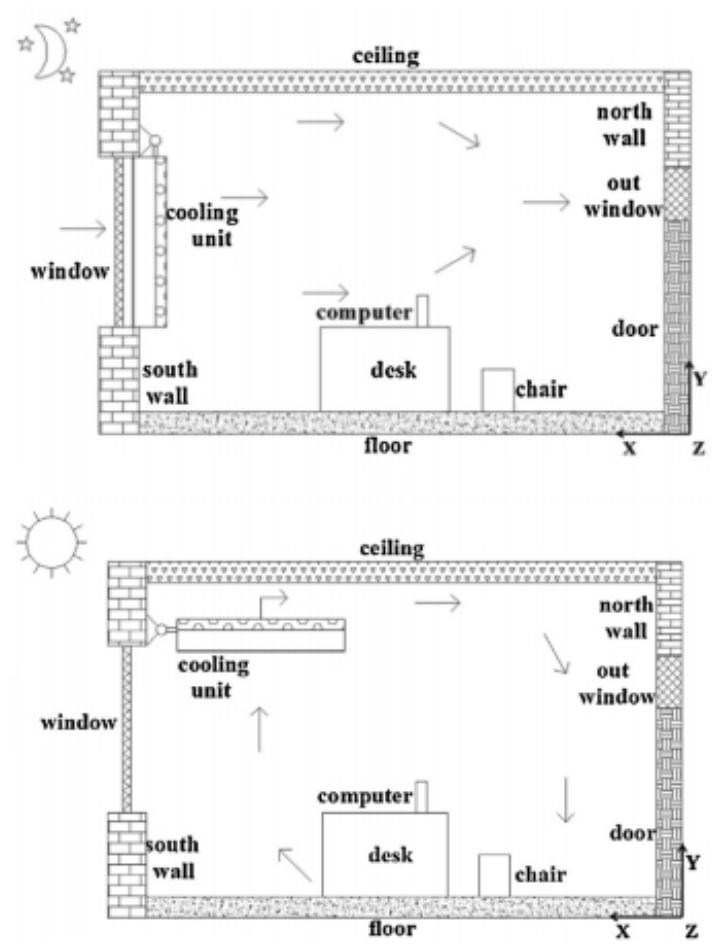

Figure 4. Operation mode: location of the cooling unit in the night (upper) and during the day (lower) [22].

Cooling unit store the coolness over the night by natural ventilation and releases it over day when temperature increase. The authors draw conclusions that proposed system enables to save the energy and improve indoor thermal comfort.

Silvaa et al. [23] were experimentally testing the performance of window shutter with phase change materials. They compared two window shutter-with PCMs and without PCMs in two compartments which were submitted to similar conditions. Fig. 5 shows investigated window shutters and blade filled with PCM.

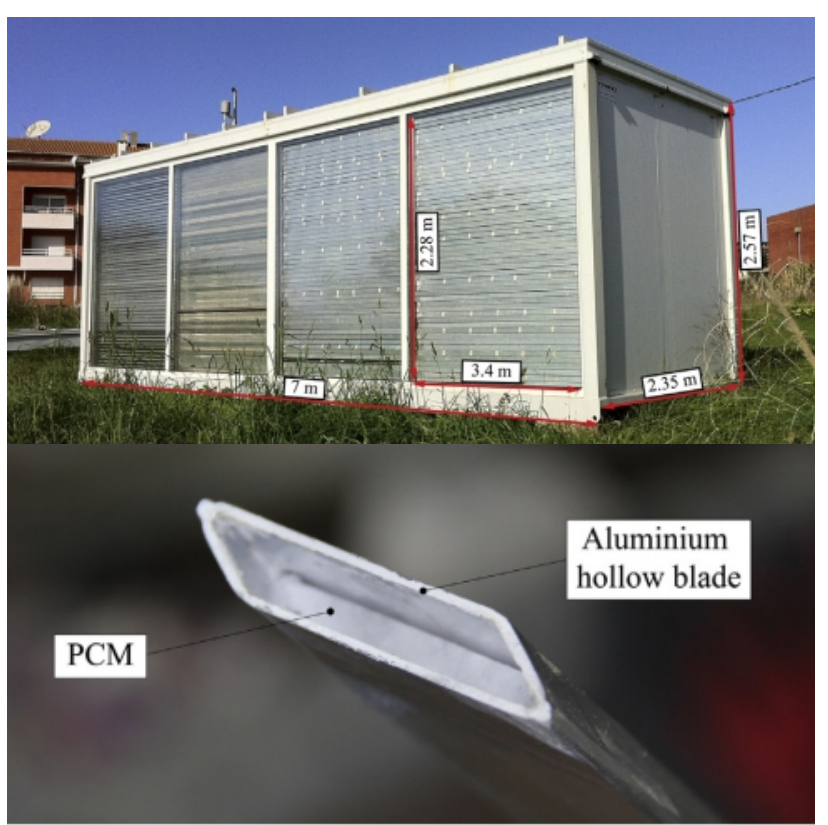

Figure 5. Investigated window shutters (upper) and window blade filled with PCM (lower) [23].

The authors commented that the results reveal potential for using phase change materials for the thermal regulation of indoor spaces as well as improving the energy efficiency of buildings. The authors pointed out in their conclusion how important it is to properly chose the material and optimize all aspects influencing indoor and outdoor conditions.

\subsubsection{Roofs}

Pisello et al. [24] focused in their study on phase change materials for roofing application. They were working on development and prototyping of an innovative cooling polyurethane based membrane with PCMs.

The authors concluded that the combination of cooling materials and thermal storage effect gives promising results as passive technique for improvement of building thermal-energy efficiency.

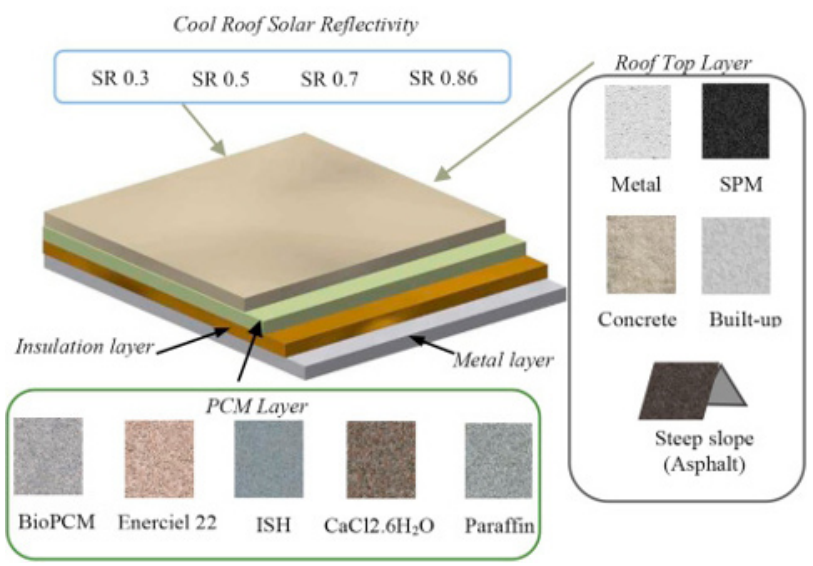

Figure 6 Graphical explanation of the various types of materials that were incorporated throughout thermal simulation study[25]. 
Roman et al. [25] conducted the comparison of two technologies. Phase change material has been compared to the cooling materials. Simulations were conducted for the range of climate zones across the United States. Various roof types and various PCM types were evaluated. Figure 6 shows graphical description of the various types of materials that were incorporated throughout simulation study.

The authors concluded that technologies with the use of PCMs are the future of energy-saving. Results shows that the PCM roof type maximum through roof heat gains flux is $54 \%$ lower than the cool roof and maximum sensible heat flux is $40 \%$ lower than the cool roof technology.

\subsubsection{Floors}

Xia and Zhang [26] proposed in their paper new doublelayer radiant floor system with organic phase change material. The new system can work either in summer and winter and the system does not need any additional refrigeration system.

Experiment has been conducted for two experimental boxes (Fig. 7) to compare the performance of different floor structures of the double-layer radiant floor system with phase change material. The environment of both boxes has been controlled.
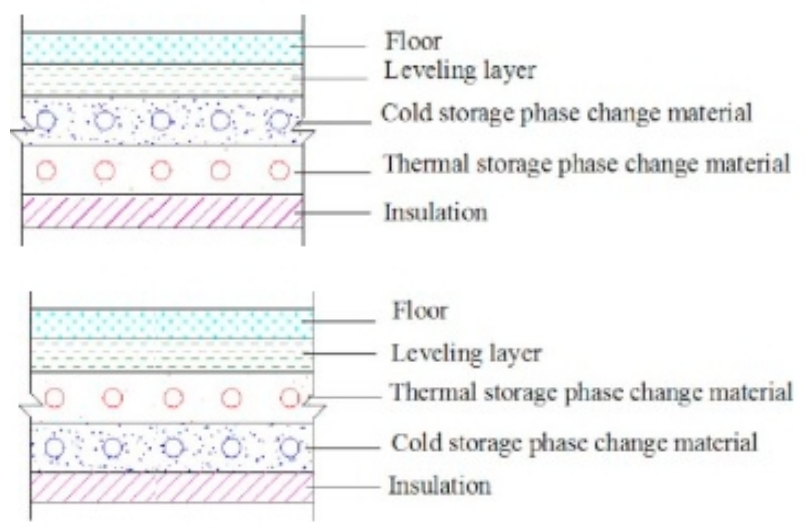

Figure 7. Two experimental floor structures [26].

Floor system proposed by Xia and Zhang can store thermal or cold energy in the off-peak period and use it in the peak period. Due to the opportunity to resign from additional refrigeration system the cost of the system will decrease.

\section{Phase change materials for solar energy}

\subsection{Photovoltaic panels}

Ciulaa et al. [27] explains the reason that photovoltaic panel (PV) performance is usually lower than expected. Performance of PV is defined for nominal conditions for the assumption that maximum electric power is supplied by the panel when it receives an insolation of $1 \mathrm{~kW} / \mathrm{m}^{2}$ and the temperature of the cell is $25^{\circ} \mathrm{C}$. Under the operating conditions solar intensity and the temperature of the panel have variable values. Many investigations are carried out to improve PV performance efficiency.
Atkin and Farid [28] conducted research and modelling to evaluate if the use of phase change material infused graphite with an external finned heat sink can be effectively used for PV thermal regulation. They compared four different thermal regulation techniques. The authors commented on results that the combined system of PCM and heat sink shows the potential of use in case of improvement of thermal conductivity.

Huang [29] was testing by numerical simulations how combination of two different PCMs (with different phase transition temperature) will impact thermal regulation effect of the system and length of the thermal regulation time in PVs. The results showed that the system with two types of PCMs can bring the PV temperature closer to its nominal value of $25^{\circ} \mathrm{C}$ and improve solar to electrical conversion.

\subsection{Solar thermal storage systems}

Phase change materials due to theirs large thermal energy storage and isothermal behaviour during phase transition are widely investigated as a possibility for solar thermal energy storage medium.

Mahfuz et al. [30] conducted experimental study to test water heating system based on shell and tube thermal energy storage system with paraffin wax to analyse its performance for solar water heating application.

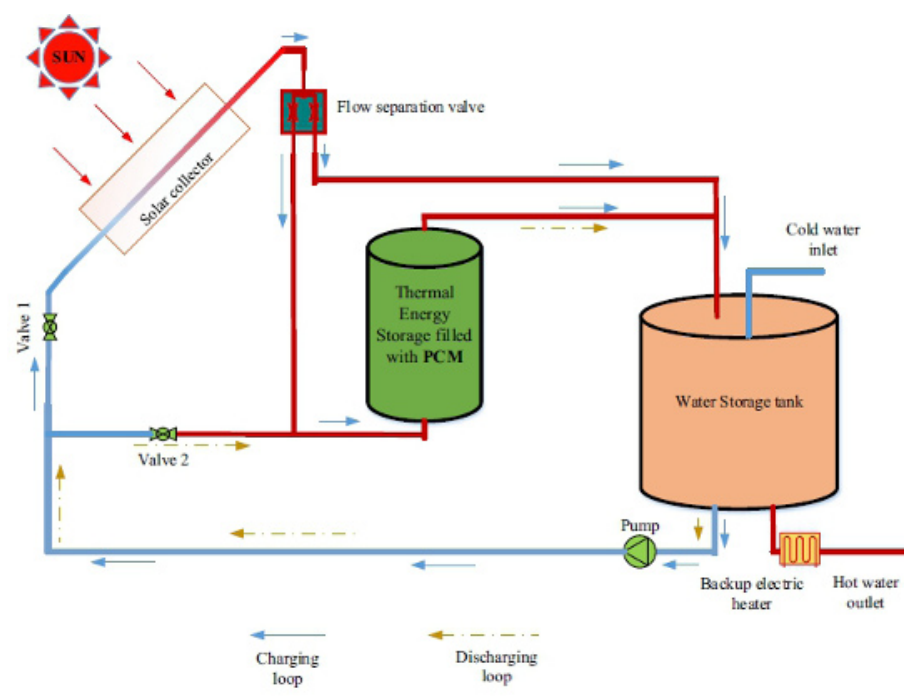

Figure 8. Solar heating water system with the termal energy storage, investigated by Mahfuz et al. [30].

Based on obtained results authors suggested some recommendations for future work related to: optimization of pipe diameter, testing different types of PCMs, testing different heat transfer fluids alternative for water, increasing of heat transfer coefficient.

Padovan and Manzan [31] investigated if application of PCMs in the thermal energy storage system in solar domestic hot water system could have good influence on system performance in the form of energy savings or reduction of TES system size. Fig. 9 shows system used for investigation and Fig. 10 shows possible positions of PCM modules. 


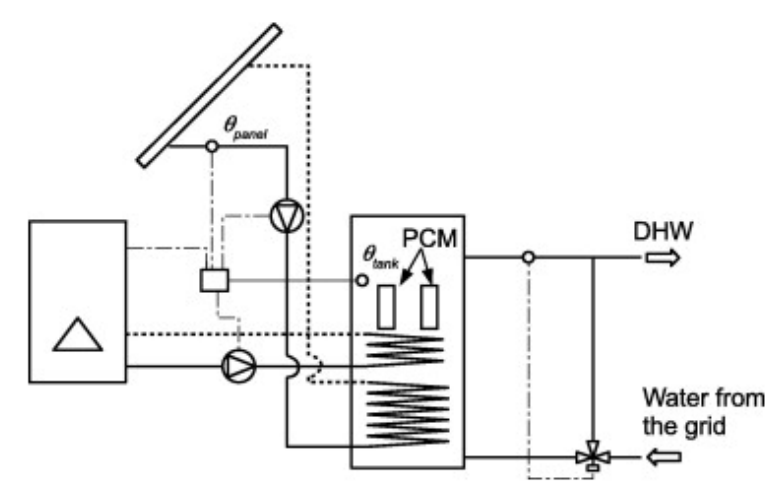

Figure 9. System investigated by Padovan and Manzan [31].

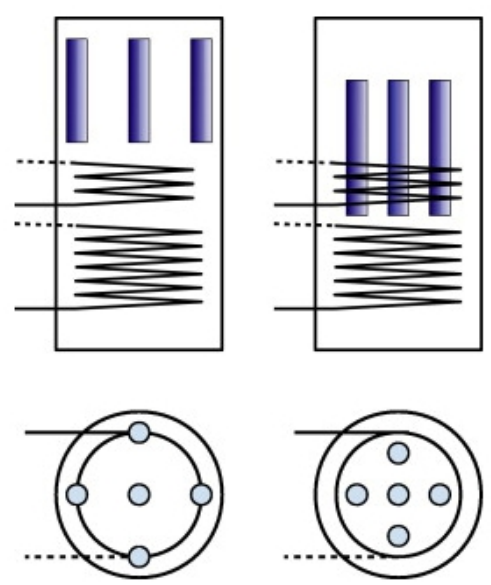

Figure 10. Possible positions of PCM modules in the PCM thermal storage investigated by Padovan and Manzan [31].

The authors concluded that addition of PCMs did not have essential impact on the results. They suggested that application of different PCMs instead of paraffin could be beneficial. It is also strongly possible that this method of application is not the best solution and would be more beneficial if system was redesigned.

\section{Phase change materials for heat pumps}

The use of heat pumps for buildings cooling and heating is assessed as efficient technology [32,33]. Additionally it may be even more productive if heat pump cooperates with thermal energy storage system. Selected examples of researches in this area are presented in this section.

Agyenim and Hewitt [34] studied RT58 PCM as a part of a wider study focused on investigation proper phase change material to take advantage of off-peak electricity tariff. Based on obtained results, the authors identified quadratic relationship between heat transfer coefficient and the inlet heat transfer fluid temperature (within temperature range $62-77{ }^{\circ} \mathrm{C}$ ). They also concluded that it is possible to reduce storage size by $30 \%$, but it is required to heat transfer techniques to charge and discharge heat form the storage.

Zhu et al. [35] carried out numerical simulation and analysis on the system of ground source heat pump integrated with PCM storage tank to study optimal control method for this system. They conducted economic analysis and analysis of energy performance for different conditions - under different cooling storage ratios. They presented an example of optimal usage of the combined system. The scheme of the combined system is presented on the Fig. 11.

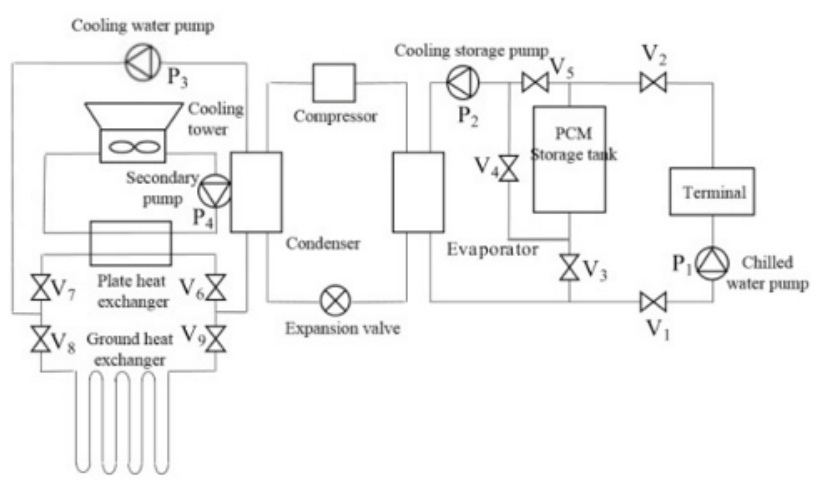

Figure 11. Scheme of combined system of ground source heat pump integrated with PCM [35].

The authors concluded that use of proposed system in comparison to ground source heat pump without PCM storage is characterised by better reliability of the operation performance and reduction of energy consumption and operation cost. Comparison of different cooling storage ratios showed that this factor affects the performance and economy. Optimal cooling storage ratio depends on building type, location and system utilization mode.

\section{Summary}

This paper reviews, based on literature, applications of phase change materials for technologies related for sustainable energy.

Application of phase change materials for technologies designed to improve energy efficiency and for technologies based on renewable energy sources have been identified by number of researchers as interesting solutions with broad potential.

Described studies are only some examples of researches conducted with the use of PCMs. Phase change materials show

Phase change materials applied in discussed technologies need to meet many criteria to be used with expected effect. The criteria that should be considered are among the others: suitable phase change temperature range, value of latent heat of fusion and thermal conductivity and compatibility with constructional materials.

Based on discussed study results, it can be identified that reasonably used phase change materials and carefully designed systems can have a large impact on improvement of technologies and thereby on energy savings.

\section{Acknowledgments}

This work was supported by AGH - University of Science and Technology (Project 11.11.210.216). 


\section{References}

1. A. Sharma, V.V. Tyagi, C.R. Chen, D. Buddhi, Renewable and Sustainable Energy Reviews 13, 318-345 (2009)

2. M. M. Farid, A. M. Khudhair, S. A. K. Razack, S. Al-Hallaj, Energy Conversion and Management 45, 1597-1615 (2004)

3. B. Zalba, J. Marin, L.F. Cabeza, H. Mehling, Applied Thermal Engineering 23, 251-283 (2003)

4. S.B. Sadineni, S. Madala, R. F. Boehm, Renewable and Sustainable Energy Reviews 15, 3617-3631 (2011)

5. S.A. Memon, H.Z. Cui, H. Zhang, F. Xing, Applied Energy 139, 43-55 (2015)

6. F. Kuznik, D. David, K. Johannes, J.-J. Roux, Renewable and Sustainable Energy Reviews 15, 379-391 (2011)

7. T. Lee, D.W. Hawes, D. Banu, D. Feldman, Solar Energy Materials \& Solar Cells 62, 217-237 (2000)

8. C. Barreneche, M. E. Navarro, A. I. Fernández, L. F. Cabeza, Applied Energy 109, 428-432 (2013)

9. H. Li, H. Chen, X. Li , J. G. Sanjayan, Applied Energy 135, 225-233 (2014)

10. L. Wang, D. Meng, Applied Energy 87 (2010) 26602665

11. Z.Zhang, G. Shi, S. Wang, X. Fang, X. Liu, Renewable Energy 50, 670-675 (2013)

12. S. A. Memon, Renewable and Sustainable Energy Reviews 31, 870-906 (2014)

13. D. Zhou, C.Y. Zhao, Y. Tian, Applied Energy 92 593-605 (2012)

14. M. Xiao, B. Feng, K. Gong, Energy Conversion and Management, 43, 103-108 (2002)

15. A. M. Khudhair, M. M. Farid, Energy Conversion and Management 45, 263-275 (2004)

16. L. F. Cabeza, C. Castellon, M. Nogues, M. Medrano, R. Leppers, O. Zubillaga, Energy and Buildings 39, 113-119 (2007)

17. Y. Zhang, G. Zhou, K. Lin, Q. Zhang, H. Di, Building and Environment 42, 2197-2209 (2007)

18. R. Fukahori, T. Nomura, Ch. Zhu, N. Sheng, N. Okinaka, T. Akiyama, Applied Energy 170, 324-328 (2016)

19. T. E. Alam, J. S. Dhau, D. Y. Goswami, E. Stefanakos, Applied Energy 154, 92-101 (2015)

20. A. Jamekhorshid, S. M. Sadrameli, M. Farid, Renewable and Sustainable Energy Reviews 31, 531-542 (2014)

21. Y. Konuklu, M. Ostryc, H. O. Paksoyd, P. Charvat, Energy and Buildings 106, 134-155 (2015) [25]

22. Y. Xiang, G. Zhou, Energy and Buildings 108, 267278 (2015)

23. T. Silvaa, R. Vicentea, F. Rodriguesa, A. Samagaio, C. Cardosoa, Energy and Buildings 88, 110-121 (2015)

24. A. L. Pisello, E. Fortunatib, S. Mattiolib, L. F. Cabezac, C. Barrenechec, J.M. Kennyb, F. Cotana, Energy and Buildings 112, 40-48 (2016)

25. K. K. Roman, T. O'Brien, J. B. Alvey, O. Woo, Energy 96, 103-117 (2016)
26. Y. Xia, X.-S. Zhang, Applied Thermal Engineering 96, 600-606 (2016)

27. G. Ciulla, V. Lo Brano, M. Cellura, V. Franzitta, D. Milone, Energy Procedia 30, 198 - 206 ( 2012 )

28. P. Atkin, M. M. Farid, Solar Energy 114, 217-228 (2015)

29. M. J. Huang, Solar Energy Materials \& Solar Cells 95, 957-963 (2011)

30. M.H. Mahfuz, M.R. Anisur, M.A. Kibria, R. Saidur, I.H.S.C. Metselaar, International Communications in Heat and Mass Transfer 57, 132-139 (2014)

31. R. Padovan, M. Manzan, Solar Energy 103, 563-573 (2014)

32. P. Moreno, C. Solé , A. Castell, L. F. Cabeza, Renewable and Sustainable Energy Reviews 39, 113 (2014)

33. M. Iten, S. Liu, A. Shukla, Renewable and Sustainable Energy Reviews 61, 175-186 (2016)

34. F. Agyenim, N. Hewitt, Energy and Buildings 42, 1552-1560 (2010)

35. N. Zhu, P. Hu, Y. Lei, Z. Jiang, F. Lei, Applied Thermal Engineering 87, 615-623 (2015) 